\title{
Information sharing as enabler for the virtual team: an experimental approach to assessing the role of electronic mail in disintermediation
}

\author{
Sheizaf Rafaeli \& Gilad Ravid \\ Graduate School of Business Administration, University of Haifa, Mt Carmel, Haifa, Israel \\ 31905, and the University of Michigan, Ann Arbor, MI, USA, email: sheizaf@rafaeli.net
}

\begin{abstract}
This paper is an attempt to document empirically the relation between information sharing accomplished via electronic mail and the performance of teams. We report on an experimental study of the role of electronic mail in the operation of supply chains. A variation of the well known 'Beer Game' role-playing simulation game was computerized and implemented in an internet-based environment to study the information-sharing behaviour of teams. A total of 76 teams of four players each competed to achieve best net team profit. Results of the simulation game permit a detailed examination of email use in an organizational context. Findings indicate the expected significant correlation between email use to share information up the supply chain and net team profit. In other words, sharing information in the team has a positive impact on performance. The recorded behaviour of managers in the online simulation indicates that team members use electronic mail successfully to attempt disintermediation of the supply chain. When information is shared online, teams perform significantly better.
\end{abstract}

Keywords: information sharing, internet, electronic mail, supply chain, team performance, organizational learning

\section{INTRODUCTION}

Information shared throughout the ranks of business organizations ought to affect organizational performance and output. This paper is about how organizational processes are embedded in the information system and articulated by it. Using a behavioural simulation, we study the relationship between sharing information via internet-delivered electronic mail and performance as it is manifested at the team level.

'Rapidly or slowly, usefully or unproductively, knowledge moves through organizations. It is exchanged, bought, bartered, found, generated, and applied to work. In contrast to individual 
knowledge, organizational knowledge is highly dynamic; it is moved by a variety of forces. If we want knowledge to move and be utilized more effectively, we need to better understand the forces that drive it.' Davenport \& Prusak (1998, p. 25).

Information sharing is one of the more intriguing behavioural impacts and potentials of the internet. Electronic mail and other communication affordances make possible new ways and larger amounts of information flows in workplace arrangements and supply chain topologies. This paper is an attempt to document empirically the relation between information sharing made possible via the introduction of electronic mail and one measure of team performance. We report on an experimental study of the role of electronic mail in the operation of supply chains. The focus here is on the behavioural impact on the team as a unit of analysis.

Increasing attention is paid to virtual team management and effectiveness (e.g. Olson et al., 1998; Carmel, 1999; Kelley, 2001). The organization of work is incorporating more virtual arrangements, all mediated through information systems. Interest in the creation, composition and performance of such teams is fuelled by the rapid adoption and implementation of electronic mail and other collaboration and communication information systems. The development and institution of virtually connected work units are accompanied by both high hopes and much trepidation. As working virtually is fairly new, there is still comparatively little empirical evidence regarding the utility, efficiency and success of virtual team arrangements. Team can be defined as a distinguishable set of two or more individuals who interact dynamically, interdependently and adaptively to achieve specific, shared and valued objectives (Weaver et al., 1997). However, what are the contributions of online technology to team effectiveness?

For the organization and people working in it, the internet in general, and communication facilities such as email in particular, are about disintermediation.

Disintermediation is defined as the elimination of intermediaries in the supply chain, sometimes referred to as 'cutting out the middlemen' (O'Rourke, 2002). Disintermediation is an especially important issue in supply chain management. Companies must consider disintermediation as a socio-technical design question. In their quest to meet the needs of demanding customers, companies have restructured, reorganized and re-engineered to increase organizational effectiveness and satisfy key customers better. The goal may be to build the very best supply chain team possible, which sometimes requires that old channel members be eliminated or replaced by new players. Thus, disintermediation can be an important part of designing a world-class supply chain. (e.g. Sampson \& Fawcett, 2001).

Disintermediation plans may be implemented in different ways in different supply chain architectures. Each topology may have its own benefits and limitations. For example, with linear supply chains, it is possible to eliminate the links between echelons allowing the outer links to transfer information directly between themselves. In other chain configurations, it may be possible to allow sharing information between all parts of the chain. Business process reengineering (BPR) and other management practices propose methods to discover the best practice in implementing the changes in the chain. This study focuses on disintermediation: changing the information flow without affecting the chain structure. 
What is the context of team behaviour within which we should evaluate electronic mail and Intranet arrangements? Modern teams operate in dynamic and changing environments. Such environments require a learning organization. To achieve efficient, flexible and adjusting teams, we need arrangements that allow team members to exchange enough information to understand and adapt to the team's goals and constraints (Senge, 1990; Sproull \& Kiesler, 1991; Senge et al., 1999). Organizations do, indeed, learn through their members but, usually, not all members possess all relevant information (Lipshitz \& Popper, 2000). Efficiency, flexibility, learning ability and a deep understanding of team goals are all needed for survival in changing environments. These are all theoretically achievable through sharing information (Sproull \& Kiesler, 1991; Olson et al., 1993; Townsend et al., 1998).

Teamwork is highly dependent on communication (Morgan et al., 1986; Mclntyre et al., 1989). Communication is central to teamwork because it links together other components such as monitoring of performance and feedback (Potter et al., 2000). Interaction styles in the team are theorized to affect performance because they can impede or enhance team members' ability to bring their unique knowledge and skills to bear on the task, and the extent to which they develop and consider alternative strategies for approaching the task (Hackman \& Morris, 1975). This is particularly critical for teams with heterogeneous levels of expertise, as communication by most expert team members is positively correlated with team performance. Bottger (1984) found that amount of communication time and expertise were positively correlated with performance, although only with high-performing teams. In their study of estimation methods for individual/team performance differences, Cooke \& Kernaghan (1987) found that average individual scores explain an average of $57 \%$ of the variance in team scores. They also noted that the expertise of the best member contributes significantly to the team score, above and beyond the average individual score, with both factors together explaining an average $69 \%$ of the variance in team score performance. Cooke \& Kernaghan (1987) also documented significant variances in relative performance among teams. Teams composed of less able individuals displayed team group process gains, whereas instances of high-potential teams (i.e. with high average individual performance scores) achieved minimal gains or even losses as a result of team processes. Team performance has usually been found to be inferior to that of the best individual. Typically, teams perform better than the average of their individual members. However, teams have been shown to do worse than their best individual member (Hill, 1982; Yetton \& Bottger, 1982; Burleson et al., 1984; Libby et al., 1987). It appears that information sharing may mediate this relationship.

Time to market is significantly reduced when information sharing is present. Both the effectiveness and the competitiveness of teams and organizations are affected by the degree of information sharing in the supply chain (Kwan, 1999). Internal and external communication within and across organizational boundaries can be used by decision makers to deliberate and solve organizational dilemmas; however, not all decision makers indeed engage in such communication (Volkema \& Niederman, 1995).

$\mathrm{Ba}$ et al. (2001) argued that, although supply chain co-ordination may be IT enabled and information sharing across the supply chain has become much easier, critical questions still remain: What information gets shared? Is the information truthful? Is there still hidden infor- 
mation that is not shared or that people are not willing to share across the supply chain? In this paper, we will attempt an experimental approach to these questions, and propose that one way of studying such issues could be through an internet-based simulation. In particular, we will explore the impact of email usage on virtual team performance. Can email use be reliably shown to impact on team outcomes?

\section{METHOD: COMPUTERIZING THE BEER GAME}

A variation on Sterman's well-known production-distribution 'Beer Game' simulation was computerized and implemented in an internet-based environment to study the information-sharing behaviour of teams. We added optional electronic mail functionality to a computerization of the Beer Game. The purpose of this development was to create an opportunity to follow the process of electronic mail use in production and supply chain processes. Doing this in a simulation context allows better control over several internal and external validity dimensions of the research question.

The Beer Game, also known as Sterman's production-distribution simulation, was developed by the Systems Dynamics Group of the Sloan School at MIT. Its manual version is described fully by Sterman (1989; 1992a,b) and Senge (1990), and widely used in the literature about supply chain management and process engineering. The game is a competition between teams. Each team works towards maximizing net team profit as the team goal. Individual participants do have data and graphs available to them regarding individual performance, but the introduction, written instructions and repeated mentions emphasize the team net profit as the purpose of the entire effort. This variable, net team profit, will serve as the central dependent variable in the present analysis. The problem that requires solution by the participating teams is how to share information correctly so that the fluctuating demand does not result in too scary a 'roller coaster ride' (Sterman, 1992a,b).

The game simulates a distribution system. Each team consists of four role positions, down the line of echelons in the supply chain: factory, distributor, wholesaler and retailer. The participants send product orders (information) up the supply chain and push products down the supply chain (see Figure 1). There is a time lag of two simulated days for each echelon between ordering and receipt. There is a similar time lag between shipping and receipt of prod-

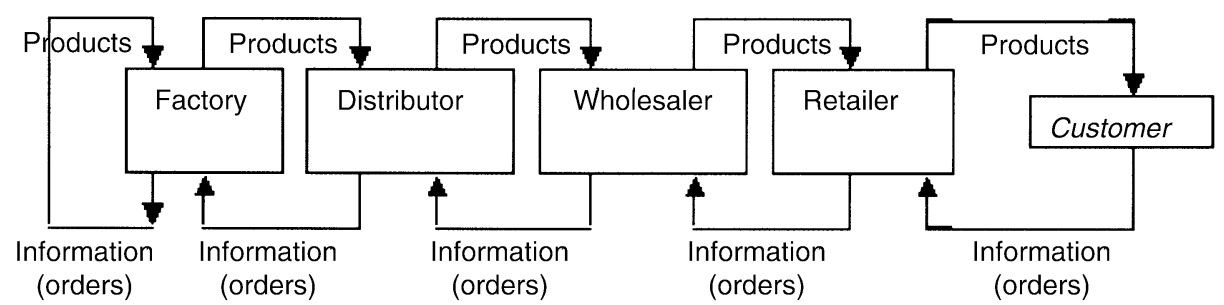

Figure 1. Supply chain topology. 
ucts. These time lags are implemented as prescribed by the software, according to a time-lag table. Participants are notified of these time lags at the outset of the game and given a table that summarizes these lags.

Each player has local information regarding his or her activities, production and financial standing. But players do not have global (system) information. Future demand is unknown to the members of the team. The game is played in multiple repeated simulated 'days'. Every simulated 'morning', the retailer is informed of the daily demand. Players may not communicate anything except order quantities. As can be seen in Figure 1, the retailer is the lowest echelon. The retailer is 'closest to the market', in the sense that the retailer is the only one in contact with the (virtual) customer, and knows the actual demand at any point in time. As the retailer has possession of the vital demand information; it is up to the person in the retail position to share this information up the supply chain.

The Beer Game has simple rules. The players make one decision per (simulated) game day. The cost structure is such that players are led to believe that they can succeed. Upon entering the game, users are often overconfident, However, they soon discover that the task is not so simple. Comments on the game, before during and after the game, indicate that, at the beginning of most games, players seem to think they have mastered the game and are sure to win. Early into the game, participants realize the role of information sharing in success. Thus, in manual classroom implementations, although the players have been asked not to pass information among themselves, it is very hard to stem the flow of chatter.

We developed an online implementation of the Beer Game (Ravid \& Rafaeli, 2000; Rafaeli \& Ravid, 2001). Since its invention, there have been several attempts to computerize the Beer Game. Among these are Jacobs' (http://jacobs.indiana.edu/beer/) internet version of the Beer Game. This game focuses on the logistic aspect of supply chain and is asynchronic. Another asynchronous game can be found at http://130.83.11.91:8080/ The Michigan Interactive Logistics Simulation game (MILS) developed by Dennis Severance and David Murray is made for local area networks. The 'Hulia' game used here (Hulia is the Hebrew word for link) is similar to the MILS game, but is internet-based, multilingual and international and synchronous in orientation. As will be discussed here, 'Hulia' also has an email-enabling feature that is the focus of this study.

The game system used here can be played entirely on the internet, with participants located anywhere. However, participants in the particular instances included in this study here were all co-located. Participants were placed in adjacent rooms. Each participant was seated next to players assuming roles in the same echelon but in different teams. Thus, some of the atmosphere and experiential aspects of the manual administration of the game were preserved. Lurking or talking to your neighbour could indicate the position of your team. Indeed, many attended to ongoing comparisons with the progress and state of the other, competing teams.

The online version used here, 'Hulia', addresses some of the manual implementation issues with the computerized game. The players sit facing a screen and not around a round table. Playing over the internet is even better because game administrators can completely manipulate, control, collect and research the informal channels of information transfer within teams. The online game keeps logs of all the transactions including information flows. The beer dis- 
tribution game, administered as a board game, has high detail complexity, very low interface complexity and a medium level of dynamics complexity. Computerizing the game did not change the mathematical model; hence, no change in the dynamic complexity. However, by moving online, we did provide a more sophisticated interface, higher interface complexity and lower detail complexity.

Thousands of students have played this simulation since the 1960s, mostly in business administration programmes. Outcomes have been reported in the literature, e.g. Sterman (1989, 1992b), Senge (1990) and Goodwin \& Franklin (1994). In the 'regular' implementation of the Beer Game, the demand function follows a prescribed pattern. According to this pattern, demand at the retail level is held almost constant, with only minor insignificant variations. The daily demand levels are raised once, several game days into the simulation, and then held constant again throughout the remainder of the simulation. As only the retailer 'knows' the demand level, the supply chain simulation becomes a test of the degree and quality of information sharing across the team. Reliably across repeated runs, the game results in negative feedback and time delays that cause oscillation, amplification and unrealistic decision making at the team level (Senge, 1990). In fact, one major lesson learned by participants involves the magnitude and cyclicity of system effects such as the difficulty in containing inventories and the whiplash nature of chain reactions. Performance and learning results of the online game are consistent with results reported in the literature (Rafaeli \& Ravid, 2001).

Figure 2 displays the main information and production cycle presented to participants in the simulation. In addition to this panel, upon which participants may make their decisions and indicate their choices, they also have access to online dynamic tables and graphs located in other panels that are available by clicking on tabs displayed in the top lefthand corner.

An additional module was developed and added to the game procedure and screen console for the purpose of this study. In some of the games, participants were offered the opportunity to correspond via email with their team mates. An electronic mail component was added. Figure 3 is a screen shot of the mail panel. With this additional module, participants had the option to send and receive electronic mail to any or all of their team mates.

As indicated earlier, the demand function in the 'regular' implementation of the Beer Game followed the prescribed pattern, in which demand at the retail level is held almost constant, with only one significant 'bump'. The version of the simulation implemented with electronic mail capabilities was incorporated with much more complex demand characteristics. Here, we used a much more volatile and less predictable seasonal demand pattern. In these instances, demand levels were changed every 4 days. For each group of 4 days, demand levels either doubled or were halved compared with the preceding 4 days. Thus, the system was a lot less stable than in the traditional form of the Beer Game. Of course, here too, participants were not told about the pattern in advance. Teams that participated in the second round of this study had access to the email version. These teams were now charged with determining the newly complex seasonal pattern of demand and communicating it up the supply chain using the email facility.

Thus, the computer-enhanced version of the Beer Game ('Hulia') allows recording and study of the process and variations of information sharing among work teams. In the traditional, board-based form of the game, participants are placed into a simulation of a realistic work sit- 


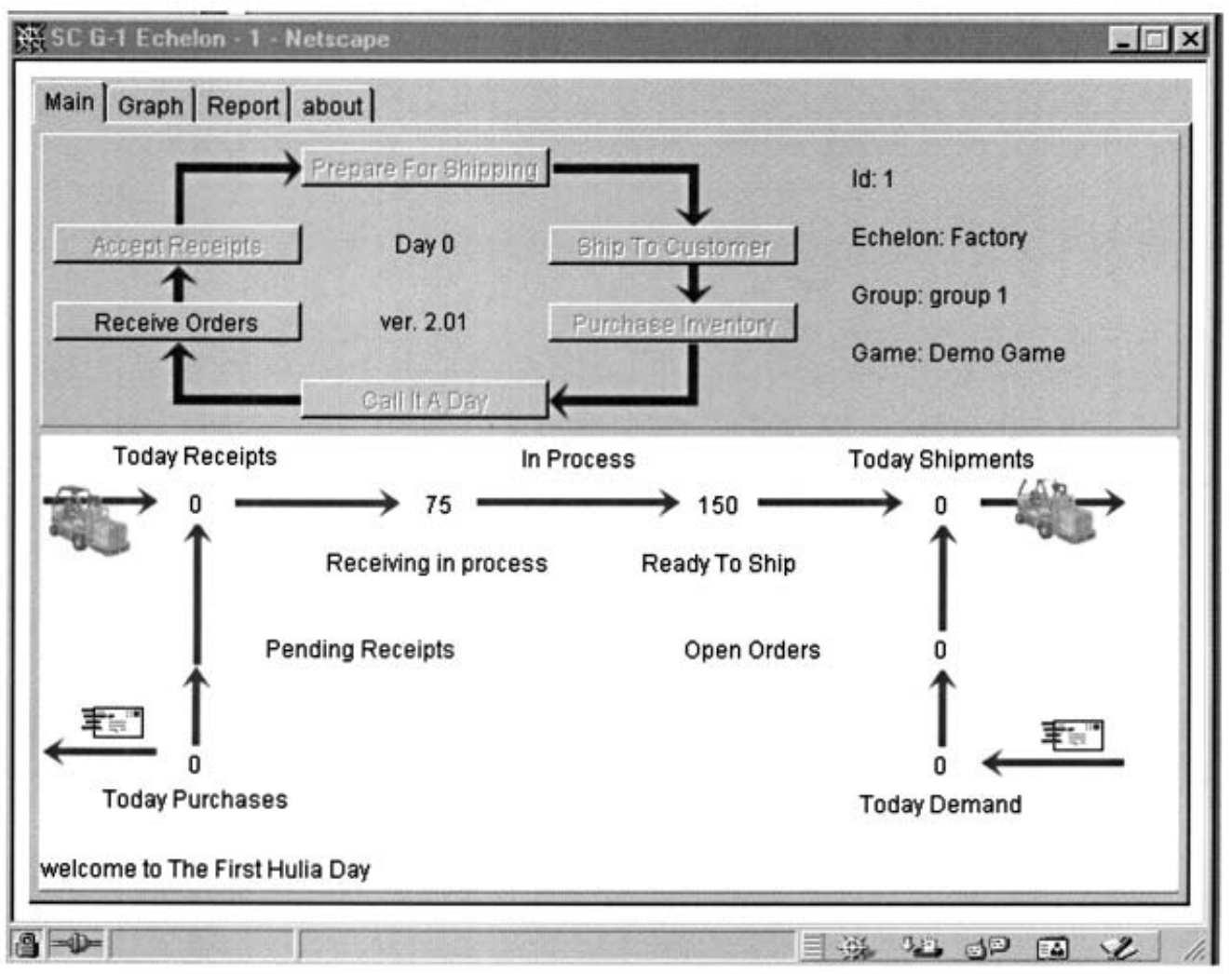

Figure 2. Screen shot of the Hulia game.

uation, in which information sharing is a requisite, although not often easy to achieve. In this version, the point of the simulation is the somewhat artificial limitation on communication. In the advanced version, we study the behavioural and organizational effect of electronic mail by removing the artificial limitation, allowing realistic, internet-based communication and information sharing.

Participants in this study were students in executive courses at a graduate school of business. The participants attended seminars on electronic business and supply chain issues. They were all current managers active in industry and service organizations, over $65 \%$ male. The simulation was used as an opening experience for the seminars. Thus, concepts such as whiplash effects and disintermediation were only introduced after the simulation. The simulation had two parts: in the first round, teams played the traditional Beer Game set-up (without email). After a debriefing session, participants played a second round that included email. All the participants played the first round; only some of them played the second round. Some teams did not play the second round because of logistics-timetable issues. However, all participants who did play the second round, with email, had previously participated in the 'regular' round. 


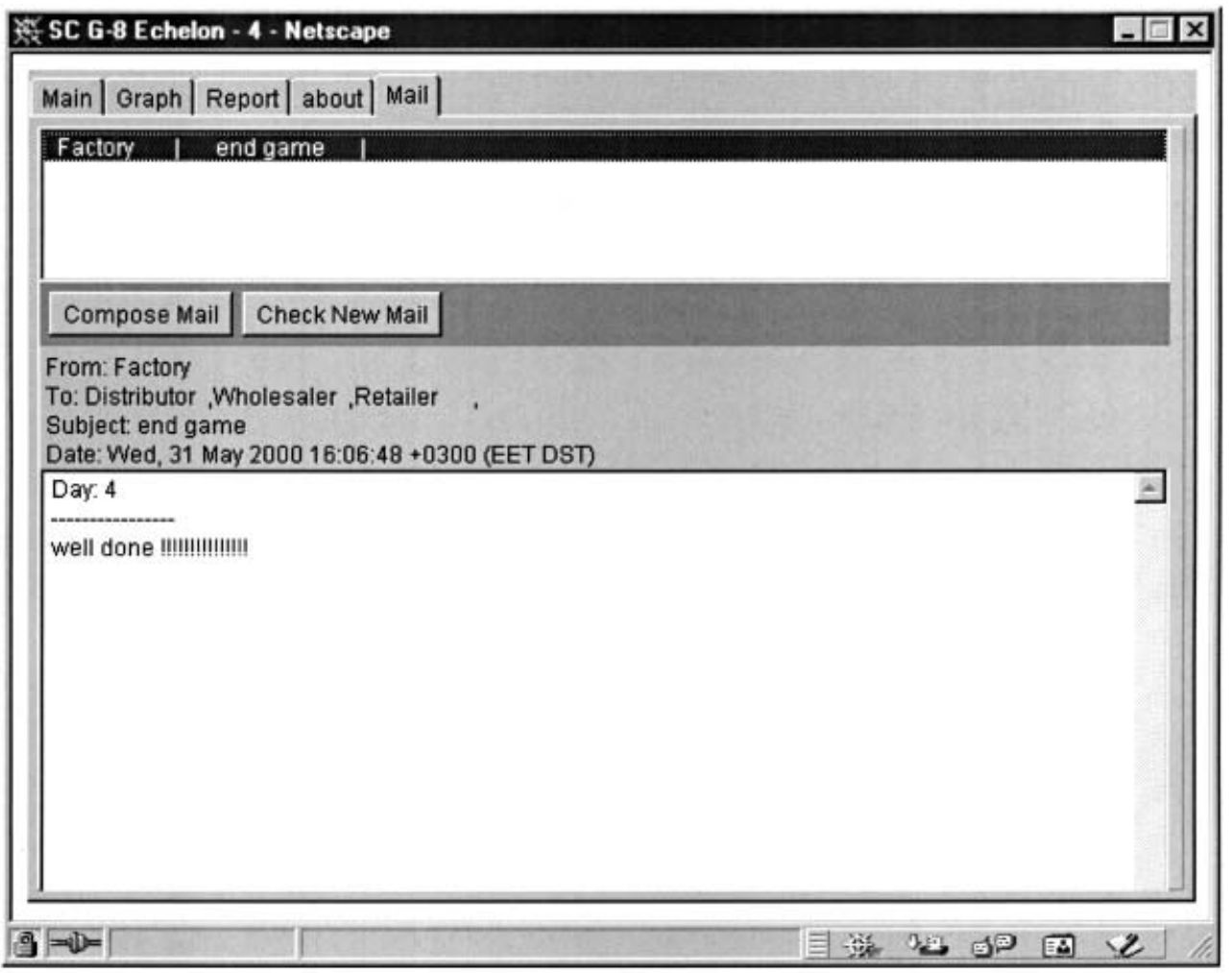

Figure 3. Screen shot of electronic mail pattern.

Participants were randomly assigned to their teams in the following fashion. Each player entered the computer laboratory and selected their own location. Only after this random choice were team number and the position in the team revealed to the player. Although players did on occasion attempt to form their own teams before the game began, actual assignments were assigned and spread randomly. This random assignment to teams and to echelons within the teams ensured experimental control elimination of extraneous variables. Team assignment was carried over from the first round and preserved in the second round. Of course, team assignments set and delimit the generalizability of our findings, as discussed below.

Participation in this simulation was a full-day experience. The simulation itself lasted up to three hours for the traditional (first round) and an additional two hours for those who completed two rounds. An introduction and debriefing were about an hour each, and the online play lasted about an hour, including a break within which players were allowed to convene in their teams and conduct a 'board of directors' face-to-face meeting. As will be shown in Table 1, 76 teams (304 participants) were exposed to the simulation. Of these, 34 teams (136 participants) experienced the simulation again, with the electronic mail functionality in operation. 
Table 1. Game data for teams in each instance

\begin{tabular}{|c|c|c|c|c|c|}
\hline $\begin{array}{l}\text { Instance serial } \\
\text { number } \\
\text { (seminar ID) }\end{array}$ & $\begin{array}{l}\text { Number of } \\
\text { teams in } \\
\text { instance }\end{array}$ & $\begin{array}{l}\text { Number of } \\
\text { game days } \\
\text { in instance }\end{array}$ & $\begin{array}{l}\text { Includes second } \\
\text { round (email- } \\
\text { enabled game) }\end{array}$ & $\begin{array}{c}\text { Standard } \\
\text { deviation of net } \\
\text { team profit }\end{array}$ & $\begin{array}{c}\text { Average } \\
\text { net team } \\
\text { profit }\end{array}$ \\
\hline 1 & 6 & 35 & & 39861.34 & -133099.0 \\
\hline 2 & 5 & 35 & & 65833.82 & -146489.6 \\
\hline 3 & 4 & 27 & & 99907.94 & -121773 \\
\hline 4 & 4 & 27 & & 84287.83 & -97242.5 \\
\hline 5 & 5 & 35 & & 31804.69 & -49603.8 \\
\hline 6 & 3 & 34 & & 40871.41 & -90613.0 \\
\hline 7 & 3 & 47 & & 526960.73 & -108818.0 \\
\hline 8 & 3 & 53 & & 544239.87 & -748649.6 \\
\hline 9 & 6 & 53† & & 148480.57 & -141358.6 \\
\hline 10 & 6 & $40 †$ & * & 47600.95 & 24798.3 \\
\hline 11 & 4 & 35 & & 63118.04 & -95387.0 \\
\hline 12 & 5 & 35 & & 89702.30 & -136353.8 \\
\hline 13 & 5 & $53+$ & & 248600.71 & -312462.4 \\
\hline 14 & 5 & 49 & * & 113135.65 & -2336.8 \\
\hline 15 & 4 & 27 & & 74386.89 & -302713.2 \\
\hline 16 & 4 & $15 \dagger$ & * & 30019.77 & 5518.7 \\
\hline 17 & 8 & 53 & & 156273.20 & -161215.7 \\
\hline 18 & 8 & 49† & * & 46621.93 & 75067.1 \\
\hline 19 & 4 & 31 & & 48832.562 & -28718.5 \\
\hline 20 & 4 & 25 & * & 94024.291 & -10835.2 \\
\hline 21 & 7 & $31 \dagger$ & & 92999.44 & -102389.5 \\
\hline 22 & 7 & 25 & * & 54559.26 & 21.4 \\
\hline Total & 110 & & & & \\
\hline
\end{tabular}

†A small number of teams completed fewer game days (no more than 5 missing days) as a result of the voluntary or accidental disconnection by one of the participants. The insignificant number of missing days should not affect the present analysis. Teams that did not complete a threshold number (have more than 5 missing days) of game days were not included in the analysis altogether.

\section{RESULTS}

The Hulia game was administered in seminars. Every seminar lasted between 4 and 12 hours. Different instances consisted of varying numbers (3-8) of simultaneous teams of four participants each. The instances also differed in the length of the game (in game days). As explained earlier, during the course of playing the second round, teams were allowed the use of electronic mail, a functionality that was built into the game simulation consoles. Because of logistical and time constraints, only some of the teams played the second round with electronic mail. In some seminars, participants played one round and, in others, participants were allowed to play twice. To allow a level playing and measuring field, all participants played the first round without email. The version of the game that included email capabilities was only used by those participants who played for the second time. In total, 22 instances (games) involved 110 team sessions of four players each. Those 110 teams consist of 42 teams who played only one round each, without email, and 34 teams who played two rounds each, the first without email and the second 
with email, for a total of 68 sessions. Data for two of the teams in the second round are not analysable. In sum, therefore, there are a total of 110 team sessions, of whom 76 played the first round (and 42 of those played only the first round). The second round, including email, was played by 34 teams and resulted in 32 useable sets of team data. Table 1 presents instance sizes in teams, length in days of each game, as well as the average and standard deviations of team net profit obtained for each instance (simultaneous administration of the game).

\section{Substudy I: do the two rounds represent the same population?}

As we have no basis for the assumption of normality or equality of variance, the Kruskal-Wallis $\mathrm{H}$-test for independent groups of sampled data was conducted for the sampled average team net profit per instance, in both the first-round instances, and within the instances with email. In both cases, the null hypothesis is that all teams were sampled from the same population. Results of both tests indicate that the null hypothesis cannot be rejected: $\chi^{2}=27.6$, d.f. $=15$, $\mathrm{sig}=0.024$ for the first-round instances. The first-round games had a high variation in the number of game days per instance. Eliminating the longest instance raises the significance beyond the threshold of $0.05-0.064$ and lowers the standard deviation of game days. In the second round, $\chi^{2}=8.056$, d.f. $=5$, sig $=0.153$ for the instances that allowed email use.

On the other hand, when comparing teams within the first round of the simulation with teams in the second-round instance in which electronic mail was allowed, we have definite support for rejecting the null hypothesis $\left(\chi^{2}=39.203 \mathrm{~d} . \mathrm{f} .=1\right.$, sig $\left.=0.000\right)$. This significant difference is probably related to the fact that all instances with electronic mail were also second rounds for all players. Learning, group formation and crystallization have taken place. As a result of better strategies that had time to form, performance was improved across the board. This performance was demonstrated even beyond the increased inherent difficulty built into the more uncertain demand pattern of the game parameters in the second, with email round.

\section{Substudy II: information sharing and team performance}

There was a negative correlation between net team profit and game length in number of game days in instances that did not contain electronic mail $(\rho=-0.246, n=76$, sig $=0.032)$. In other words, the longer the simulation was held (in game days), the higher was the team loss. On the other hand, the correlation between game length and the desired outcome of net team profit was positive for those instances that had electronic mail between echelons ( $\rho=0.445, n=32$, $\mathrm{sig}=0.011$ ). The positive correlation may be related to learning and group formation. Our data do not speak directly to this. However, further analysis within the round that allowed use of electronic mail does shed some light on the relationship between information sharing and team performance. Throughout the rest of this study, we will conduct and report statistical analyses only within the round exposed to email, respecting the differences between teams.

Email use varied significantly across echelons. While participants in the factory position sent only two or three messages to other positions on average per game, retailers used the email function much more heavily. We can describe this measure as the in- and out-degree of cen- 
Table 2. Messages sent between each pair of roles (echelons)

\begin{tabular}{lcccc}
\hline Sender & $\begin{array}{c}\text { Messages sent } \\
\text { to retailer }\end{array}$ & $\begin{array}{c}\text { Messages sent to } \\
\text { wholesaler }\end{array}$ & $\begin{array}{c}\text { Messages sent } \\
\text { to distributor }\end{array}$ & $\begin{array}{c}\text { Messages sent } \\
\text { to factory }\end{array}$ \\
\hline Factory & 3.66 & $\mathbf{2 . 4 1}$ & 3.50 & $\mathbf{0 . 2 0}$ \\
Distributor & 3.67 & 3.38 & 5.12 & 0.41 \\
Wholesaler & $\mathbf{2 . 5 4}$ & 3.95 & $\mathbf{0 . 6 8}$ & $\mathbf{3 . 4 0}$ \\
& 3.31 & 5.84 & 0.94 & 3.73 \\
Retailer & $\mathbf{4 . 1 3}$ & 1.27 & 4.04 & 3.54 \\
& 5.10 & 3.11 & 6.01 & 5.42 \\
\end{tabular}

Mean number of messages per team through game in bold. Standard deviation per team in italics.

Based on data from 32 teams participating in the simulation with seasonal demand and electronic mail.

Table 3. Spearman rho correlations of order levels and standard deviations between echelons in instances without electronic mail

\begin{tabular}{|c|c|c|c|c|c|c|c|c|}
\hline \multirow[b]{2}{*}{$n=76$} & & \multicolumn{2}{|c|}{ Factory } & \multicolumn{2}{|c|}{ Distributor } & \multicolumn{2}{|c|}{ Wholesaler } & \multirow{2}{*}{$\frac{\text { Retailer }}{\text { Mean order }}$} \\
\hline & & Mean order & $\sigma$ order & Mean order & $\sigma$ order & Mean order & $\sigma$ order & \\
\hline Factory & $\sigma$ order & $0.790^{* *}$ & & & & & & \\
\hline \multirow[t]{2}{*}{ Distributor } & Mean order & $0.726^{* *}$ & $0.591^{* *}$ & & & & & \\
\hline & $\sigma$ order & $0.627^{* *}$ & $0.645^{\star *}$ & $0.704^{* *}$ & & & & \\
\hline \multirow[t]{2}{*}{ Wholesaler } & Mean order & $0.550^{* *}$ & $0.453^{* *}$ & $0.699^{* *}$ & $0.579^{* *}$ & & & \\
\hline & $\sigma$ order & $0.458^{* *}$ & $0.488^{* *}$ & $0.531^{* *}$ & $0.648^{* *}$ & $0.737^{* *}$ & & \\
\hline \multirow[t]{2}{*}{ Retailer } & Mean order & $0.440^{* *}$ & $0.384^{* *}$ & $0.509^{* *}$ & $0.446^{* *}$ & $0.656^{* *}$ & $0.473^{* *}$ & \\
\hline & $\sigma$ order & $0.232^{*}$ & $0.253^{*}$ & $0.263^{*}$ & $0.352^{* *}$ & $0.384^{* *}$ & $0.530^{* *}$ & $0.617^{* *}$ \\
\hline
\end{tabular}

${ }^{*}$ Correlation is significant at the 0.05 level (two-tailed).

${ }^{* *}$ Correlation is significant at the 0.01 level (two-tailed).

trality as used in the social network analysis (SNA) method. The number of messages sent by any echelon is a measure of out-degree centrality, whereas the number of messages received by any echelon indicates in-degree centrality. Mail was used most for disintermediation attempts by retailers communicating over the head of the rest of the supply chain directly to those in the factory position. However, retailers were also very likely to send more emails to the wholesalers and distributors as well. An examination of the diagonal from the right-upper corner to the left-bottom corner of Table 2 is interesting too. This diagonal reports on the degree to which participants used the 'CC' function to send themselves copies of the messages they sent to others (the cells in this diagonal are shaded). This function was used very sparsely by the factory, distributor and wholesaler positions.

Turning now to an analysis of the relationship between order levels in the different echelons. Tables 3 and 4 display this relation with regard to the instances and teams with and without email respectively. Table 3 reports that, in the absence of electronic mail, there was a significant, consistent correlation between echelons in the mean number of orders as well as their variation (standard deviation). As can be expected, the correlation, although still significant, 
Table 4. Spearman rho correlations of order levels and standard deviations between echelons in instances with electronic mail

\begin{tabular}{|c|c|c|c|c|c|c|c|c|}
\hline \multirow[b]{2}{*}{$n=32$} & & \multicolumn{2}{|c|}{ Factory } & \multicolumn{2}{|c|}{ Distributor } & \multicolumn{2}{|c|}{ Wholesaler } & \multirow{2}{*}{$\frac{\text { Retailer }}{\text { Mean order }}$} \\
\hline & & Mean order & $\sigma$ order & Mean order & $\sigma$ order & Mean order & $\sigma$ order & \\
\hline Factory & $\sigma$ order & $0.769^{* *}$ & & & & & & \\
\hline \multirow[t]{2}{*}{ Distributor } & Mean order & $0.764^{* *}$ & $0.439^{\star *}$ & & & & & \\
\hline & $\sigma$ order & $0.668^{* *}$ & $0.801^{* *}$ & $0.535^{\star *}$ & & & & \\
\hline \multirow[t]{2}{*}{ Wholesaler } & Mean order & 0.206 & 0.039 & $0.685^{\star *}$ & 0.312 & & & \\
\hline & $\sigma$ order & 0.326 & $0.496^{* *}$ & $0.370^{*}$ & $0.863^{* *}$ & 0.342 & & \\
\hline \multirow[t]{2}{*}{ Retailer } & Mean order & $0.435^{*}$ & 0.312 & $0.531^{* *}$ & 0.353 & $0.643^{* *}$ & 0.227 & \\
\hline & $\sigma$ order & 0.216 & 0.300 & 0.104 & $0.434^{*}$ & 0.165 & $0.647^{* *}$ & 0.119 \\
\hline
\end{tabular}

${ }^{*}$ Correlation is significant at the 0.05 level (two-tailed).

${ }^{* *}$ Correlation is significant at the 0.01 level (two-tailed).

Table 5. Linear regression of net team profit by number of messages (information sharing) and game length (game days)

\begin{tabular}{llll}
\hline Model & \multicolumn{1}{c}{ Independent variable } & $R^{2}$ & Significance \\
\hline 1 & Number of messages sent by retailer & 0.375 & 0.000 \\
2 & Length of simulation in game days & 0.079 & 0.12 \\
3 & Number of messages sent by retailer and length of simulation in game days & 0.396 & 0.000 \\
\hline
\end{tabular}

erodes as the distance between echelons increases. Thus, for instance, the retailers' mean order levels and variation in orders are correlated more highly with the order levels of the wholesaler than with those of the distributor and even less with the factory.

On the other hand, the correlation pattern in Table 4 indicates that, in the second, more complex iteration of the game, when electronic mail was available to the teams, and the demand pattern was much more erratic and unpredictable, correlations between echelon order levels deteriorated.

Information sharing in the Beer Game context with electronic mail can be operationalized as the number of electronic mail messages sent between echelons. The correlation between the number of messages sent by the retailer and net team profit was both high and significant $(\rho=0.665, n=32$, sig < 0.000). However, a fairly high correlation was found between the number of messages sent by the retailer and game length as well $(\rho=0.618, n=32$, sig $<0.000)$. In other words, a possible alternative explanation for this central relationship between information sharing is that longer games lead to more sharing and also produced higher net team profits.

Linear regressions were run to investigate this alternative explanation further. Table 5 presents the $R$-square for three models of linear regression in predicting net team profit. The net profit can be explained by two variables: the number of messages sent by the retailer, and the length of simulation in game days. Recall that the hypothesis focuses on the retailer. Retailers, in this game and in real life, interface with the virtual market and must deal with the challenge of getting information from the market to flow up the supply chain. Retailers need to instigate this communication even if it means disintermediating the other levels in the supply chain. Table 5, as well as a stepwise regression, suggested that a model with only the number of mes- 
sages explains as much variance in the team's profit as the combined model. These results permit us to explain the net profit by number of messages sent by the retailer.

The linear correlations of the regression outcomes indicate that there exists a positive, high correlation between the number of messages sent by the retailer and net team profit. In other words, sharing information in the team has a positive impact on performance.

\section{DISCUSSION}

Building upon a tradition of study of electronic mail use at the individual level, this study focused on the team as the unit of analysis of interest. The results reported here provide some support to the hypothesis that disintermediation might be the information systems-based response to supply chain whiplash issues.

The results reported in the previous section are of interest on a variety of levels. Most importantly, these results provide empirical support for the hypothesized relation between information sharing and team profit, the operationalization used in this simulation for performance. Participants in the simulation reported here used electronic mail most often for task-related purposes, in a manner that attempted to compensate for the structural problems built into the Beer Game supply chain emulation. As Sterman (1992a) and Senge (1990) predicted, structure does indeed influence behaviour. The provision of email makes a difference, and its use is differentiated by role in the supply chain.

The contribution of this study is in providing documentation and support for the expected effect of electronic mail in the real world. As the results reported here were generated in a simulated business environment, the study has conditions that are both experimental (internal validity) and fairly generalizable (externally valid). The method described here highlights the supply chain model for teams. The findings underline the notion of disintermediation as an organizing construct for analysing success and failure of electronic mail impacts on organizational performance.

In addition, these results may serve as support for the use of business game simulations in the study of team behaviour and organizational processes, especially in the context of online and virtual environments. Most research on behavioural impacts of the technology in the literature to date relating to these environments has been based on snapshot surveys or conducted in synthetic laboratory experiments such as Sproul \& Kiesler's (1991) classic series of studies, and Olson et al.'s (2000) seminal work on distance and supporting virtual team work. Simulations, such as the one reported here, allow examination of processes and documentation of temporal relations.

Several methodological cautions should apply to the method used and the results reported here. One problem with our data is that all teams who operated with electronic mail had prior exposure to the simulation under the traditional conditions, without electronic mail. Further, the teams in round two were identical to those in the first round. These facts do not invalidate the findings, as the correlations of interest were found within that round. Furthermore, the procedure emulates many real-life situations, in which electronic mail may be introduced after peri- 
ods of activity before the availability of online communication. These data are presented and analysed at the team level, with no focus provided here to individual differences. Instead, we chose to examine process and structural constructs.

This approach and these results also suggest directions for future investigation. The design used here is not the only experimental design that could be based on this simulation, and the dependent variable under examination here is not the only dependent variable that can be trapped in this design.

Given the cost of requiring an entire day of participants' involvement, the flexibility of the experimental design was limited. Future runs of similar seminars may allow other experimental contrasts, such as randomly assigning teams to different communication ecologies and comparing same teams' performance with and without disintermediation. These contrasts are not permitted by our data. Furthermore, net profit may not be the only dependent variable of interest. For example, the availability of email may affect participant satisfaction or team commitment and cohesion. Predictions regarding the effects of the information system architecture of the process could be tested against these more subtle variables as well. Future research may also address individual differences, going beyond the team level analysis performed here.

In the quest for improved information systems, and in accordance with the trends of developing computerized systems with more active participation in message formation and direction, further use of this simulation can provide additional research opportunities. Future investigations will examine the actual content of electronic mail exchanges, which are available for scrutiny using this research method. There is the opportunity to seek correspondence between recorded discourse and information exchange on the one hand, and subjective reactions and interpretations on the other.

To summarize, this was a study of information systems-mediated information sharing in a simulated business situation. The main finding in this study is a positive, high correlation between the amount of appropriate information sharing within teams and the net team profit achieved in a well-understood business setting. When online technology allows information flows, teams that share information appropriately perform better.

\section{REFERENCES}

Ba, S., Stallaert, J. \& Whinston, A. (2001) Optimal investment in knowledge within a firm using a market mechanism. Information Systems Research, September, 225-239.

Bottger, P.C. (1984) Expertise and air time as bases of actual and perceived influence in problem-solving groups. Journal of Applied Psychology, 69, 214-221.

Burleson, B.R., Levine, B.J. \& Samter, W. (1984) Decisionmaking procedure and decision quality. Human Communication Research, 10, 557-574.
Carmel, E. (1999) Global Software Teams: Collaborating Across Borders and Time Zones. Prentice Hall, New York.

Cooke, R.A. \& Kernaghan, J.A. (1987) Estimating the difference between group versus individual performance on problem-solving tasks. Group and Organization Studies, 12, 319-342.

Davenport, T.H. \& Prusak, L. (1998) Working Knowledge: How Organizations Manage What They Know. HBS Press, Boston, MA. 
Goodwin, J.S. \& Franklin, S.G. (1994) The Beer Distribution Game: using simulation to teach systems thinking. Journal of Management Development, 13 (8), 7-15.

Hackman, J.R. \& Morris, C.G. (1975) Group tasks, group interaction process, and group performance effectiveness: a review and proposed integration. In: Advances in Experimental Social Psychology, Vol. 8, Berkowitz, L. (ed.), pp. 45-99. Academic Press, New York.

Hill, G.W. (1982) Group versus individual performance: are $\mathrm{N}+1$ heads better than one? Psychological Bulletin, 91 , 517-539.

Kelley, E. (2001) Keys to effective virtual global teams. The Academy of Management Executive, 15 (2), 132-133.

Kwan, A.T.W. (1999) The use of information technology to enhance supply chain management in the electronic and chemical industries. Production and Inventory Management Journal, 40 (3), 7-15.

Libby, R., Trotman, K.T. \& Zimmer, I. (1987) Member variation, recognition of expertise, and group performance. Journal of Applied Psychology, 72, 81-87.

Lipshitz, R. \& Popper, M. (2000) Organizational learning in a hospital. Journal of Applied Behavioral Science, 36, 345-361.

McIntyre, R.M., Salas, E., Morgan, B. \& Glickman, A.S. (1989) Team Research in the 80s: Lessons Learned. Naval Training Systems Center, Orlando, FL.

Morgan, B.B.J., Glickman, A.S., Woodard, E.A., Blaiwes, A.S. \& Salas, E. (1986) Measurement of Team Behaviors in a Navy Environment. Naval Training Systems Center, Orlando, FL.

Olson, J.S., Covi, L., Rocco, E., Miller, W.J. \& Allie, P. (1998) A room of your own: what would it take to help remote groups work as well as collocated groups? Paper Presented at the $\mathrm{CHI}$ 98, Los Angeles, CA, USA.

Olson, J.S., Olson, G.M., Storrosten, M. \& Carter, M. (1993) Groupwork close up: a comparison of the group design process with and without a simple group editor. ACM Transactions on Information Systems, 11, 321-348.

O'Rourke, S. (2002) Disintermediation [online]. Crucial marketing-internet marketing consulting. [WWW document]. URL http://www.marketingterms.com/dictionary/ disintermediation/.

Potter, R.E., Cooke, R.A. \& Balthazard, P.A. (2000) Virtual team interaction: assessment, consequences, and management. Team Performance Management, 6, 131-137.

Rafaeli, S. \& Ravid, G. (2001) Research through online simulation of team coordination, communication, and information sharing. Paper Presented at the INFORMS
Section on Group Decision and Negotiation and EuroGDSS Group Decision and Negotiation 2001. La Rochelle, France.

Ravid, G. \& Rafaeli, S. (2000) Multiplayer, internet and Java-based simulation games: learning and research in implementing, a computerized version of the 'BeerDistribution Supply Chain Game'. Paper presented at the Web-based Modeling and Simulation WEBSIM, San Diego, CA, USA.

Sampson, S.E. \& Fawcett, S.E. (2001) The impact of disintermediation in retail supply chains. Paper presented at the POM conference, Orlando, FL, USA.

Senge, P.M. (1990) The Fifth Discipline: The Art and Practice of the Learning Organization, 1st edn. Currency Doubleday, New York, NY, USA.

Senge, P.M., Kleiner, A., Roberts, C., Ross, R., Roth, G. \& Smith, B. (1999) The Dance of Change: The Challenges of Sustaining Momentum in Learning Organizations. Currency Doubleday, New York.

Sproull, L. \& Kiesler, S. (1991) Connections: New Ways of Working in the Networked Organization. The MIT Press, Cambridge, MA.

Sterman, J.D. (1989) Modeling managerial behavior: misperceptions of feedback in a dynamic decision making experiment. Management Science, 35, 321-339.

Sterman, J.D. (1992a) The beer distribution game: an annotated bibliography covering its history and use in education and research. [WWW document]. URL http:// www.sol-ne.org/pra/tool/bibl.html

Sterman, J.D. (1992b) Teaching takes off: flight simulation for management education. [WWW document]. URL http://web.mit.edu/jsterman/www/SDG/beergame.html

Townsend, A.M., DeMarie, S.M. \& Hendrickson, A.R. (1998) Virtual teams: technology and the workplace of the future. Academy of Management Executive, 12 (3), 17-30.

Volkema, R.J. \& Niederman, F. (1995) Meeting the challenge: application of communication technologies to group interactions. Paper Presented at the SIGCPR 95, Nashville, TN, USA.

Weaver, J.L., Bowers, C.A., Salas, E. \& Cannon-Bowers, J.A. (1997) Motivation in teams. In: Advances in Interdisciplinary Studies of Work Teams, Vol 4: Team Implementation Issues, Beyerlein, M.M., Johnson, D.A. \& Beyerlein, S.T. (eds), pp. 167-191. Jai Press, Greenwich, UK.

Yetton, P.W. \& Bottger, P.C. (1982) Individual versus group problem solving: an empirical test of a best-member strategy. Organizational Behavior and Human Performance, 29, 307-321. 


\section{Biographies}

Sheizaf Rafaeli (PhD Stanford University) is Director of the Center for the Study of the Information Society and a Professor at the Graduate School of Business Administration, University of Haifa, Israel. His interests include information sharing and the value of information, mediated interaction, synchronicity, simulations, online behaviour, groups and decision making. He has taught in numerous universities in Israel, Europe and the US, including the Hebrew University of Jerusalem, Stanford University and the University of Michigan. Sheizaf has published in the field of computermediated communication and has been involved in studying and building internet-based activities such as online higher education, journalism, political, governmental, social and commercial virtual organizations. He is co- author of Network and Netplay (MIT Press) and co-founder of the Journal of Computer-Mediated Communication.

Gilad Ravid (BSc in Agricultural Engineering, Technion - the Israel Institute of Technology, MBA specialization in Management Information Systems and Operations Research, Hebrew University of Jerusalem, and doctoral student at the University of Haifa, Israel) is Manager of the Technical Group in the Center for Information Technology and Distance Education at the Open University of Israel. $\mathrm{He}$ is a lecturer at the Hebrew University of Jerusalem and the Ruppin Institute. Gilad has published in the areas of distance education, supply chain management simulations and group online communication. 